\title{
The Role of Conformational Traits on Dairy Cattle Production and Their Longevities
}

\author{
Addis Getu1, Godadaw Misganaw ${ }^{2}$ \\ ${ }^{1}$ University of Gondar, Gondar, Ethiopia \\ ${ }^{2}$ Aksum University, Shire Campus, Aksum city, Ethiopia \\ Email: addisgetu2002@yahoo.com
}

Received 17 February 2015; accepted 4 March 2015; published 9 March 2015

Copyright (C) 2015 by authors and OALib.

This work is licensed under the Creative Commons Attribution International License (CC BY). http://creativecommons.org/licenses/by/4.0/

\section{(c) (i) Open Access}

\begin{abstract}
The dairy industry faces a unique challenge to constantly improve functionality of the dairy cows to meet the needs of future production and reproduction demands. The basis of improvements is selection of the best animals. The accuracy of selection can be increased by using the combined analysis of both direct information on herd life and indirect information obtained from conformation traits. Generally, conformation traits are important in dairy cattle development. These traits are used for selection of animals through creating the predict equation based on the independent variable and assuring selection of the superior animal with its important trait. The functional conformation traits that influence or facilitate the longevity and reproduction status of dairy cows are the appearance of udder conformation, feet and leg conformation, thoracic and abdominal body conformation, and rump and loin structure. The relationship between conformation traits with milk production and reproduction traits might be different among breeds, which could have implications for the use of conformation traits in different dairy cattle breeding programmes. The estimated correlations between longevity and different conformation traits are also varying with breeds.
\end{abstract}

\section{Keywords}

Dairy Cattle, Conformation Trait, Longevity

Subject Areas: Animal Behavior, Genetics

\section{Introduction}

Conformation traits are known to be important to dairy producers that dairy cows produce milk efficiently and look appealing in doing so, over a long productive lifetime. As a result, conformation traits are recorded in many of the modern dairy cattle breeds. These traits have been known to have modern to high heritability and often can be recorded in a single assessment, which makes them reliable and relatively cheap traits that can be in- 
cluded in selection indices for several purposes [1]. Pure size traits, such as stature and heart girth, are closely related to body weight [2], which are important functional traits regulating feed efficiency and energy balance traits in dairy cattle [3]. Feed efficiency and energy balance traits in turn are key traits for the biological and economic efficiency of dairy production [4]. Other conformation traits such as dairy character, muscularity and body condition score (BCS) could be expected to be more specifically related to metabolic reserves and indicative of problems associated with a negative energy balance [5].

The relationships among body conformation measurements of dairy cows represent a special interest to the diary industry. Most of the dairy farmers usually judge the merits of dairy cows, to a certain extent, on the basis of body conformation. Brum and ludwick [6] found that measurements of body capacity such as body length, heart girth and withers height were related to milk production. The udder of the cow is one of the most important criteria that can be used to predict production performance [7]. The phenotype of better udder height is positively correlated to better genetic potential at first lactation. The udder conformation and teat attachments are related to udder health and the efficiency of machine milking. Cows with high score of body measurements of live animal in the herd, not being called for a health problem. Rogers et al. [8] found that udder depth and teat rear view were the traits most related to survival. Selection based on body measurements and milk production could result in a greater genetic gain in milk yield than single selection for milk yield.

Solkner et al. [9] underline that longevity in cow is an integral part of selection in cattle breeds with dual purpose. Auxiliary traits which indirectly influence the length of productive life in dairy cows are body conformation traits, classified when body conformation classification, mainly feet, legs and mammary system.

In the minds of many people, especially producers, longevity is also the most important trait associated with dairy production. This belief is quite understandable since the length of time that a cow remains in the herd reflects her ability to meet or surpass the herd owner's minimum expectations. Therefore, Longevity, reproduction and total milk production in cows become the important traits among selection criteria criterions, which have tight connections to economic effectiveness of milk production [10].

Dairy cow survival is influenced by many genetic and non-genetic factors. Non-genetic factors include the housing type, milk quota restrictions and the availability of replacement heifers. Genetic factors include the capability for high production and desirable milk components, the functional conformation necessary for a cow to express her productive and reproductive potential, the ability to maintain adequate body condition to resist metabolic disorders and maximize immune status, and the ability to move with sound locomotion [11]. In most countries milk and reproductive performance recording is limited to relatively small numbers of dairy animals. This is in part due to the high cost of recording, and thus much higher per unit cost of milk produced, since the genetic merit of breeding animals is not assessed by more exact methods. The question has been raised in dairy animals as to whether consideration of physical conformation in addition to production data may increase selection response or reduce it.

Therefore, the overall objectives of the paper are:

$\checkmark$ To assess the contribution of conformation traits in dairy cattle production;

$\checkmark$ To describe the effect of conformation traits on longevity and reproduction.

\section{The Use of Conformation Traits in Dairy Production}

The dairy industry faces a unique challenge to constantly improve functionality of the dairy cow to meet the needs of future production and reproduction demands. Today's classification program focuses on a comprehensive set of descriptive traits that describe the animal's strengths and weaknesses and that collectively depict overall functionality. Since conformation traits are heritable and have been shown to be linked with functionality, selection for conformational traits is an effective tool to facilitate genetic improvement in functionality [11].

In Ethiopia the roll of conformation traits in our indigenous dairy cattle improvement program is not well done and described. Genetic improvement can be made through selection and, mating those selected animals. Therefore, due to the lack of appropriate selection and judgment criteria through conformation traits to our indigenous dairy cattle, its significance in our indigenous milking cow improvement is almost minimal.

\subsection{Selection Criteria}

We are equipped with more accurate selection and evaluation tools than at any time in the past. However, sound decision-making is still dependent on superior cow sense and good conformation trait appearances [11]. While great advancements have been made in the productivity of the modern dairy cow through genetic selection, in 
some respects developments in cattle husbandry, housing and the facilities or technologies used on dairy farms have not kept pace, resulting in problems such as less than optimal cow comfort levels or nutrition. So for immediate, short term improvements in mobility, it is advisable to look at improvements in herd management, cow comfort levels and nutrition. Genetic selection for good locomotion and feet and leg conformation, however, has an important role to play in long term reduction of lameness levels and careful consideration as part of the overall breeding improvement within a herd is therefore recommended.

Genetic change and hopefully improvement takes place when the parents of the next generation of animals are chosen. For a dairy herd, that means choosing the sires and dams of potential heifer replacements and doing so on the basis of their expected genetic merit. The information necessary in making the selection decisions on which sires and dams will be the parents of the next generation of heifer replacements. This kind of genetic evaluation needs information that combines the direct information on heard life from a survival analysis with the indirect information derived from breeding values for conformation traits [12]. It is an accepted principle that the more characteristics for which one selects, the less progress is made. Therefore, it would be advisable to restrict selection criteria for dairy cattle on milk production, fat and protein yield, feet and legs, udders, capacity, dairyness. Each will be analyzed separately. For instance, collectively selection for these six characteristics would go a long way to ensuring more productive dairy cows in South Africa [13]. The effect of selection for milk yield which might imply that selection of dairy cattle has been exclusively for milk yield. Although selection for yield traits has received primary emphasis in the selection goals of dairy breeds and substantial emphasis has been placed on other traits.

In our country, Ethiopia the selection criteria for indigenous breeding females are related to production traits. However, some conformation traits are also subjectively appraised and incorporated to selection criteria in most of the smallholder farmers. Selection criteria relevant to milk production potential are includes bigger size of the udder and teat, pedigree history of the animal indicating inheritance from a known high producer as recalled by owner, well attached udder and squarely placed teats. Related conformation traits include wide hindquarter, long and thin tail, longer naval flap, thin and long neck, concave face, reduced hump, attractive appearance, drooping vulva (for easiness of calving), bushy tail end, thick skin (to withstand the infliction of biting flies) and big body size. Other relevant traits include temperament, non-black hair coat, better growth rate; good mothering ability and being in good health condition also take in mind [14].

\subsection{Basis of Judgment}

Generally judgment is practiced depending on the different types of conformation traits. Judging dairy cattle is a comparative evaluation of cattle in which animals are ranked based on their closeness to "ideal" dairy conformation. Desirable dairy conformation involves functional traits associated with high milk production over a long and trouble free productive life. In addition to learning how to judge cattle, many life skills are gained through the dairy judging experience. In order to judge dairy cattle, knowing the parts of a cow, ideal dairy conformation, and how to describe differences between animals will provide us with the necessary tools to place classes. In addition, good judges of dairy cattle need a definite mental image of the ideal animal for the breed being judged. This image can be developed by observing the body conformations of cattle at shows, visiting outstanding herds, studying breed journals, and observing personally-owned dairy cattle closely [15].

The Purebred Dairy Cattle Association (PDCA) in United State of America for Holstein cows developed a score card that describes ideal dairy conformation that focuses and evaluating five major categories are frame, dairy character, body capacity, feet and legs, and udder [15]. Surprisingly, there is no clear indigenous dairy cattle judgment criteria based on the morphological appearance (body conformation) of the cows in Ethiopia. Most of the Ethiopian farmers judge their dairy cows by considering the history of high daily milk yield, high fat content and shorter age at first calving and calving interval. However, in some part of the country like Mulu-Sululta, Degem and Addis Ababa some specific conformation traits are considered to be related to dairy cows productivity. These are small head size and, almost all the farmers considered a cow as best for milk production if it has a straight back, triangular shape of the frame of a cow and straightness of the back of the cow and large udder of the cow [16].

\subsection{Indicators of Milk Yield}

Several conformation phenotypes are identified as important predictors of milk estimated breeding values, if they are measured early in life before milk estimated breeding values are computed, and if these predictors have 
no known negative side-effects on cows' profitability, then those conformation traits could be used for mating decision-making. Indeed, dairy producers are usually able to evaluate their cows' conformation. This information could then be used before milk estimated breeding values are available, or when they are not available [17].

In India the different conformation traits are assessed in relation to milk yield of the different local cattle breeds. The result shows that some cows that have non prominent naval flaps but proportionate and medium sized teats are average milk yielders. On the other hand cows that have voluminous dewlap and large naval flap, well developed udder and teats with prominent milk vein are docile and good milk yielders. Cows that have short and tacked up naval flap, long and well round barrel, small compact udders and small hard teats are also poor milkers [18].

For instance, the phenotypic correlations between conformation traits and milk production of Holstein ranged from (0.35to 0.75). For Brown Swiss, these phenotypic correlations were less strong (0.08 to 0.19), and also for Red and White heifers ( 0.15 to 0.19 ). However, phenotypic correlations between conformation traits and fat and protein production were very low and near zero in Holstein, but reached values near 0.20 for Brown Swiss and Red \& White [19]. While, the genetic correlations of milk production with conformation traits in Holstein were all positive, except for Body BCS (condition score). In Brown Swiss, however, muscularity and rump width showed negative correlations with milk production. For Red \& White, only muscularity was negatively correlated with the milk production. The directions and trends estimated for the genetic correlations between conformation traits and both fat and protein production were similar to each other for all breeds, and SCS (somatic cell score) was generally negatively, or just slightly positively, correlated with the conformation traits, although it showed moderate values for some traits in the Red \& White breed [19].

\section{Improving Reliability of Genetic Evaluation}

Generally, the reliability of genetic evaluation is defined as a squared correlation between the true and the estimated breeding value of an animal. Methods that use both direct information on heard life and indirect information obtained from conformation traits have recently been developed by [20]. Both information sources are combined into one index after being appropriately weighted depending on reliability and genetic covariance's between conformation traits and heard life. The procedure that combines the direct information on heard life from a survival analysis with the indirect information derived from breeding values for conformation traits is computationally simple and can be applied to any bull that has conformation proofs. The reliability of the combined evaluation is always higher than the reliability of the direct evaluation alone [12].

\section{The Effect of Conformation Traits in Longevity and Reproduction}

The consistent improvement in physical conformation and a significant proportion of genetic variation in longevity remains unexplained by existing type or production traits. Some bulls that transmitted outstanding production and type still had daughters that tended to leave the herd prematurely. Therefore, type traits can be used as an indirect indicator of expected longevity of a bull's daughters but actual culling and fertility data are needed to explain the rest of the story. We must recognize that daughter fertility and survival are important profitability traits. These are dependent not only on conformation and productivity traits but also on the general health and physiology of the cow, as well as the cows' resiliency to the stress of high production and confinement housing. More recently, emphasis on tall and large frames has been directed more to a focus on an angular, open and well-sprung rib accompanied by a wide chest and sufficient depth of body to provide the functionality necessary to consistently produce large amounts of milk. Sufficient stature is still required to achieve the necessary balance with a desirable skeletal frame that provides the strength to support a strong loin and a properly sloped rump. The rump represents the prominences of the pelvis and its importance in feet and leg structure, udder width and attachment, as well as calving ease cannot be over estimated. A strongly attached and well-balanced udder with fine texture will support high and persistent production over the cow's lifetime [11]. Generally, the functional conformation traits that influences or facilitates to the longevity and reproduction status of dairy cows are classified in to four groups. These are udder conformation, feet and leg conformation, thoracic and abdominal body conformation, and rump and loin structure

\section{Udder Conformation}

Evaluation of udder conformation and the relative importance placed on each trait has been modified over the 
years. Any discussion of udder conformation should include a detailed description of the udder's suspensor apparatus since this attachment to the ventral abdominal wall and the pelvic floor is fundamental to udder health and longevity [11]. The udder's exterior form and location depend on the development and strength of its suspensor apparatus which is responsible for the attachment of the udder to the ventral abdominal wall and the pelvic floor. Many of the undesirable changes in the udder's exterior characteristics and location can be attributed to a weakness of the suspensor apparatus and these changes are usually irreversible. Normal maturity will cause the suspensor ligament to stretch and excessive stretching or tearing can cause pendulous udders, which are more prone to injury and infection.

Historically, the udder was located in a more anterior position and was attached only to the abdominal wall much the same as with deer or elk. Udder shape, location, and strength of attachments are hereditary. Heritability of udder traits were estimated to be between 0.14 and 0.42 [1]. Therefore genetic selection has the ability to alter anatomical structure of the cow's udder. Selection for increased production has caused the udder to increase in size and mass. As a result the udder's centre of gravity has shifted caudal or posterior and the suspensor apparatus of the udder has been supplemented with additional support tissue that attaches to the pelvic floor by means of the symphysial tendon. Evaluating fundamental anatomical characteristics such as udder depth and suspensor udder strength has facilitated the development of a functionally sound udder to accommodate the stress of high production. Several researchers have shown a consistent relationship between udder conformation and udder health and longevity. VanDorp et al. [21] showed that cows with longer teats were genetically predisposed to a higher incidence of mastitis. In addition, cows may alter their gait if udders are deep and pendulous. Udder traits (especially the height of the udder above the hock) were found to positively influence the length of productive life. Udder depth and milking ease accounted for $84 \%$ of the total contribution of type traits to functional longevity [22]. Recent Canadian data reported that rear teat placement, udder depth, and udder texture were udder traits that had a significant influence on functional survival [23].

\section{Feet and Leg Conformation}

Breed societies and breeding companies acknowledge the value of good feet and leg conformation and now routinely include them as traits as part of conformation assessments on cows. Being able to measure and subsequently produce genetic information on feet, legs and locomotion traits, we now have the ability to pick bulls, which improve these traits as part of the overall breeding improvements within a herd.

Locomotion is a qualitative observation of a cow's ability to walk normally. It should evaluate the cow's conformation and motion biomechanics, her freedom from lameness, and the desirability of the surface upon which she walks. Scoring locomotion directly is the most accurate determination of a cow's feet and leg soundness. In addition to evaluating the magnitude of lameness, locomotion scoring has been initiated in several countries as part of the type classification system. For instance, in Canada locomotion is being evaluated as a research trait in free stall herds. Locomotion evaluation involves observing a cow while walking and identifying important step parameters including foot placement and length of stride. Normal locomotion is characterized by a long fluid stride where the rear foot falls into the position vacated by the front foot on the same side (no abduction or overlap). Undesirable locomotion may result in the rear foot being placed outside the imprint of the front foot as well as a reduction in the stride length, and a decrease in step angle and walking speed [24].

Several researchers have shown relationships between feet and leg traits and clinical lameness. Wells et al. [25] showed that a 10-degree drop in foot angle resulted in an odds ratio of 2.4 to develop clinical lameness. The estimated heritability of feet and leg traits is low, ranging from 0.08 to 0.30 [1], however, the most influential type trait on profit, after adjusting for production, was shown to be Feet and Legs [26]. This association can be attributed to the positive influence that sound feet and legs can have on reproduction and longevity. A favorable genetic correlation was estimated between Feet and Legs and non-return rate, suggesting that cows with good feet and legs were less likely to return to service [27]. Melendez et al. [28] explained that cows having foot and leg problems were less likely to show signs of estrous. Sewalem et al. [23] reported that cows having extremely course bones, extremely shallow heels, low foot angle, and extremely straight or curved legs from the side view had decreased functional longevity.

\section{Thoracic and Abdominal Body Conformation}

The Canadian Holstein has long been recognized around the world for her capacity, made possible by well 
sprung, open ribs, and for the unique combination of chest width and body depth that give rise to her characteristic angularity. Although extreme height and size in the show ring has been preferred historically, stature and size have been shown to have negligible effects on longevity [23]. The classification system in Canada has progressed alongside knowledge of relationships between body traits and longevity. As a result size is no longer evaluated and stature does not receive as much emphasis, contributing less than $3 \%$ to the Final Score. In Cana$\mathrm{da}$, a cow having an angular, open and well-sprung rib with a wide chest and sufficient depth of body is desired to support the ability to produce large amounts of milk.

Studies have demonstrated the relationships between body shape and survival in dairy cows. Cows that were extremely short, small and narrow-chest had a higher risk of being culled compared to cows intermediate for these traits. A clear relationship between angularity and longevity was observed, indicating that extremely non-angular cows were 2.47 times more likely to be culled than those with intermediate angularity. Additionally, extremely angular cows had a 1.28 times better chance of surviving than cows that are intermediate angularity [23].

Relationships between body condition and reproductive performance are well documented. Cows with high genetic merit for BCS lost less body condition in early lactation, and therefore experienced less severe negative energy balance [29]. In addition, Dechow et al. [29] reported that the genetic correlation between body condition loss and days to first service was 0.68 in first lactation and 0.44 in second lactation, indicating that as body condition loss became more severe, days to first service increased. Kadarmideen and Wegmann [30] found similar favorable genetic correlations between fertility (days to first service and non-return rate) and BCS. Dechow et al. [29] noted that selection for yield appears to increase body condition loss by lowering postpartum BCS. Cows that were thinner (lower body condition) had longer calving intervals [31]. Thoracic and abdominal capacity along with dairyness and femininity (angularity) are desirable attributes to facilitate the dairy cow's ability to process large volumes of roughage and sustain high production and desirable reproductive performance [11].

\section{Rump and Loin Structure}

A dairy cow's rump connects several other anatomical structures of significance through the pelvic region. The hind legs articulate with the pelvis at the thurls, the udder attaches to the abdominal wall by way of the prepubic tendon and to the pelvis floor by way of the suspensory ligaments: is directly attached to the pelvis at the lumbo-sacral junction. Essentially, the rump and loin structures fasten the cow's abdominal and lumbar regions to her feet and legs and mammary system. Without adequate strength in this area, the productive life of a cow will be seriously compromised [11].

The position of the hook and pin bones define the allowable width of the pelvis to accommodate a desirably high and wide rear udder. A wide, correctly sloped rump is characteristic of pelvic structure that allows for easier passage for the calf at birth and necessary drainage of post-calving fluids in order to prevent metritis infections and fertility related problems. Ali and Schaeffer [32] described the ideal rump phenotype for ease of calving as one having pin bones that are slightly lower than hook bones, a vulva almost vertical when viewed from the side, collectively displaying a long and wide rump with a well-defined pelvic arch. Finally, absence of abnormalities such as advanced anus, advanced tail head, and recessed tail head are desired so that fertility is not negatively affected.Higher pin bones are associated with an undesirable tilt to the vaginal canal causing it to lie at an inward sloping angle rather than lying flat. With this type of angle, the reproductive tract is more prone to infection because the vagina is unable to drain effectively [33]. During parturition, the natural exit path for a calf is at a downward angle. Higher pins have a genetic association with inefficient longer calving intervals [27]. Research shows that animals with higher pin bones and narrower rumps are more likely to have difficult calving [34]. In addition, cows with high and narrow pin bones had an increased genetic predisposition to retained placentas [21]. According to VanDorp et al. [21] showed that cows with lower scoring rumps were genetically prone to a higher incidence of lameness. In addition to its positive effect on reproduction; researchers have reported a strong link between a sloped wide rump structure and increased longevity. Animals with intermediate rump angles (slope of 1 - 2 inches from hook to pin) had a longer productive life (lower rate of culling) than animals with extremely low or extremely high pin bones in relation to hip bones [26]. Sewalem et al. [23] showed that the relative risk of involuntary culling was lowest at intermediate rump angles.

\section{Relations between the Length of Productive Life and Body Conformation Traits}

One implication of the indirect selection for longevity in dairy cows is the application of the correlated traits, 
which show the potential of the individual from a young age and are related to its survival in the herd. From the main and partial traits mainly the body conformation traits, the legs and the udder conformation were regarded.

Hansen et al. [34] found out that dairy cows of the Holstein breed with smaller body size reached a higher length of productive life at the levels of 72 months of age and 84 months of age in comparison with dairy cows with bigger body size. Similar results are confirmed for Simmental cattle mainly in Germany and Austria, which have populations of the Slovak Simmental cattle with different body size [35]. Vukasinovic et al. [12] present a genetic correlation between longevity and body length $(\mathrm{r}=0.39)$ and body depth $(\mathrm{r}=0.42)$ in Brown Swiss cattle. A positive relation between body size or body height and longevity is presented by Cassandro et al. [35] and [36].

The cows with sound conformation of the rear legs, the fetlock and the feet reach a longer productive life. Longer productive life in cows with a correct rear leg set in all husbandry systems and found low or moderate genetic correlations of rear leg posture $(r=0.35)$, foot angle $(r=0.25)$ and fetlock $(r=0.21)$ in Brown Swiss cattle [12].

Vukasinovic et al. [12] found significant genetic correlations between longevity and the evaluation of the udder and the teats ( $\mathrm{r}$ ranged from 0.38 to 0.66). Similar findings are presented by Burke and Funk [37], especially for simmentalized breeds in Europe. Strapak et al. [36] and Vacek et al. [38] suggest well attached for udder, high attached rear udder, strong central ligament, close front teat placement and moderately long teats as important traits for a long productive life.

\section{Conclusions}

Conformation traits are known to be important to dairy producers. Dairy farmers usually judge the merit of dairy cows to a certain extent on the basis of body conformation. Judgment is practiced depending on different conformation traits. Judging dairy cattle is a comparative evaluation of cattle in which animals are ranked based on their closeness to "ideal" dairy conformation. Selection of dairy cows is also accompanied by the measurements and observations of the different conformation traits. These traits are also in turn best indicators of milk yield. The most advisable selection criteria to get real dairy cows are milk production, and conformation traits (udders morphology, dairyness or body shape, body capacity, feet and leg set, and fat and protein yield). Selection efficiency, measured by the correlation between the index and the aggregate genotype, increases production when conformation traits are included in the selection criteria for milk yield. As a result, conformation traits are recorded in many of the modern dairy cattle breeds in the most developed countries.

Fertility and survival are important profitability traits. These are dependent not only on conformation and productivity traits but also on the general health and physiology of the cow, as well as the cows' resiliency to the stress of high production and confinement housing. Therefore, reproduction, total milk production and longevity in cows become the important traits among selection criteria criterions, which have tight connections to economic effectiveness of milk production. Genetic selection for good locomotion and feet and leg conformation, however, has an important role to play in long term reduction of lameness levels and careful consideration as part of the overall breeding improvement with in a breed is recommended. Genetic evaluation needs information that combines the direct information on herd life from a survival analysis with the indirect information derived from for conformational traits.

\section{Recommendation}

In most developing countries, recording of production and reproduction performance is not well practiced and limited to relatively small numbers of dairy animals, due to high cost of recording and relatively time consuming. On the other hand recording of conformation traits can be done easily in a single assessment. Therefore, it is might be appropriate the use conformation traits for selection of dairy cattle instead of simply waiting to attain recording potential;

$>$ Specifically to our country, the use of conformation traits in relation with production and reproduction performance of indigenous dairy cattle is negligible. In addition to this we haven't any standard recording farm and experiences, sufficient economic potential and the existing environmental conditions also not suitable to do it. Due to this reasons the indigenous dairy cattle is not well evaluated and there is no enough improvement activities. Therefore, conformation traits should be perfectly evaluated its relation with production and reproduction performance of dairy cows and genetic improvement could be started through conformation 
traits;

> To increase the reliability of genetic evaluation of dairy cows, the production and reproduction data should be also aggregated with the assessment of conformation traits;

$>$ Conformation traits should be evaluated perfectly according to their contributions to the production life time of the cow(longevity) and selection criteria for best milking animals should be consider the possibility of longevity (long and trouble free production time).

\section{References}

[1] Kistemaker, G. and Huapaya, G. (2006) Parameter Estimation for Type Traits in the Holstein, Ayrshire and Jersey Breeds. (Mimeo) Dairy Cattle Breeding and Genetics Committee Report to the Genetic Evaluation Board.

[2] Mantysaari, P. (1996) Predicting Body Weight from Body Measurements of Pre-Pubertal Ayrshire Heifers. Agricultural and Food Science in Finland, 5, 17-23.

[3] Lin, C.Y., Lee, A.J., McAllister, A.J., Batra, T.R., Roy, G.L., Veseley, A.J., Wauthy, J.M. and Winter, K.A. (1987) Inter Correlations among Milk Production Triats and Body and Udder Measurements in Holstien Hefiers. Journal of Dairy Science, 70, 2385-2393. http://dx.doi.org/10.3168/jds.S0022-0302(87)80299-0

[4] Koenen, E.P.C. (2001) Selection for Body Weight in Dairy Cattle. Ph.D. Thesis, Wageningen University, Wageningen, 258.

[5] Wells, S.J., Trent, A.M., Marsh, W.E., McGovern, P.G. and Robinson, R.A. (1993) Individual Cow Risk Factors for Clinical Lameness in Lactating Cows. Preventive Veterinary Medicine, 17, 95-109. http://dx.doi.org/10.1016/0167-5877(93)90059-3

[6] Brum, E.W. and Ludwick, T.M. (1999) Heritabilities of Certain Immature and Mature Body Measurements and Their Correlations with First Lactation Production of Holstein Cows. Journal of Dairy Science, 52, 52-85.

[7] Vukasinovic, N., Moll, J. and Kunzi, N. (1995) Genetic Relationships among Longevity, Milk Production and Type traits in Swiss Brown Cattle. Livestock Production Science, 41, 11-18. http://dx.doi.org/10.1016/0301-6226(94)00044-8

[8] Rogers, G.W., McDaniel, B.T., Dentine, M.R. and Johnson, L.P. (1981) Relationships among Survival Rates, Predicted Differences for Yield and Linear Type Triats. Journal of Dairy Science, 56, 389-412.

[9] Sondergaard, E., Sorensen, M.K., Mao, I.L. and Jensen, J. (2002) Genetic Parameters of Production Feed Intake, Body Weight, Body Composition, and Udder Health in Lactating Dairy Cows. Livestock Production Science, 77, 23-34. http://dx.doi.org/10.1016/S0301-6226(02)00023-4

[10] Meszaros, G., Fuerst, C.H., Fuerst-Waltl, B., Kadlečík, O., Kasarda, R. and Sölkner, J. (2008) Genetic Evaluation for Length of Productive Life in Slovak Pinzgau Cattle. Archives of Animal Breeding/Archiv Tierzucht-Index, 5, 438-48.

[11] Atkins, G., Shannon, J. and Muir, B. (2008) Using Conformational Anatomy to Identify Functionality \& Economics of Dairy Cows. WCDS Advances in Dairy Technology, 20, 279-295.

[12] Vukasinovic, N., Schleppi, Y. and Kunzi, N. (2002) Using Conformation Traits to Improve Reliability of Genetic Evaluation for Herd Life Based on Survival Analysis. Journal of Dairy Science, 85, 1556-1562. http://dx.doi.org/10.3168/jds.S0022-0302(02)74225-2

[13] John, P.B. (2005) Breeding and Selection of Dairy Cows.

[14] Taye, T. (2005) On-Farm Phenotypic Characterization of Sheko Breed of Cattle and Their Habitat in Bench Maji Zone, Ethiopia. Master's Thesis, Alemaya University, Dire Dawa, 105.

[15] Seykora, T. and Hansen, L. (2000) Judging Dairy Cattle. Jessica Stamschror, Undergraduate, College of Agricultural, Food, and Environmental Sciences, University of Minnesota, St. Paul.

[16] Belihu, K. (2002) Analyses of Dairy Cattle Breeding Practices in Selected Areas of Ethiopia. Ph.D. Dissertation, Department of Tropical and Sub-Tropical Animal Breeding and Acquaculture of the Humboldt University of Berlin, Berlin, 164.

[17] Detilleux, J.C. and Leroy, P. (1999) Genetic Evaluation of Type Traits in Northern Part of Belgium. Proceedings of the Open Session of the International Bull Evaluation Service Annual Meeting, Prague, 89.

[18] Manoj, S., Gurdeep, S. and Baljit, S. (2008) Know about Important Breeds of Dairy Cattle and Buffaloes in India. 27 p.

[19] de Haas, Y., Janss, L.L. and Kadarmideen, H.N. (2007) Genetic and Phenotypic Parameters for Conformation and Yield Traits in Three Swiss Dairy Cattle Breeds. Journal of Animal Breeding and Genetics, 124, 12-19.

[20] Weigel, K.A., Lawlor, T.J., Van Raden, P.M. and Wiggans, G.R. (1998) Use of Linear Type and Production Data to Supplement Early Predicted Transmitting Abilities for Productive Life. Journal of Dairy Science, 81, 2040-2044. http://dx.doi.org/10.3168/jds.S0022-0302(98)75778-9 
[21] Ali, T.E., Burnside, E.B. and Schaeffer, L.R. (1984) Relationships between External Body Measurements and Calving Difficulties in Canadian Holstein-Friesian Cattle. Journal of Dairy Science, 67, 3034-3044. http://dx.doi.org/10.3168/jds.S0022-0302(84)81669-0

[22] Larroque, H. and Ducrocq, V. (2001) Relationship between Type and Longevity in the Holstein Breed. Genetics Selection Evolution, 33, 39-59. http://dx.doi.org/10.1186/1297-9686-33-1-39

[23] Sewalem, A., Kistemaker, G.J., Miglior, F. and Van Doormaal, B.J. (2004) Analysis of the Relationship between Type Traits and Functional Survival in Canadian Holsteins Using a Weibeull Proportional Hazards Model. Journal of Dairy Science, 87, 3938-3946. http://dx.doi.org/10.3168/jds.S0022-0302(04)73533-X

[24] Telezhenko, E. (2002) Cow Tracks and Floor Choices. International Lameness Symposium. Poster, Orlando.

[25] Waltner, S.S., McNamara, J.P. and Hillers, J.K. (1993) Relationships of Body Condition Score to Production Variables in High Producing Holstein Dairy Cattle. Journal of Dairy Science, 76, 3410-3419. http://dx.doi.org/10.3168/jds.S0022-0302(93)77679-1

[26] Pérez-Cabal, M.A. and Alenda, R. (2002) Genetic Relationships between Lifetime Profit and Type Traits in Spanish Holstein Cows. Journal of Dairy Science, 85, 3480-3491. http://dx.doi.org/10.3168/jds.S0022-0302(02)74437-8

[27] Wall, E., White, I.M.S., Coffey, M.P. and Brotherstone, S. (2005) The Relationship between Fertility, Rump Angle, and Selected Type Information in Holstein-Friesian Cows. Journal of Dairy Science, 88, 15-21. http://dx.doi.org/10.3168/jds.S0022-0302(05)72821-6

[28] Melendez, P., Bartolome, J., Archibald, L.F. and Donovan, A. (2003) The Association between Lameness, Ovarian Cysts and Fertility in Lactating Dairy Cows. Theriogenology, 59, 927-937. http://dx.doi.org/10.1016/S0093-691X(02)01152-4

[29] Dechow, C.D., Rogers, G.W. and Clay, J.S. (2002) Heritability and Correlations among Body Condition Score Loss, Body Condition Score, Production and Reproductive Performance. Journal of Dairy Science, 85, 3062-3070. http://dx.doi.org/10.3168/jds.S0022-0302(02)74393-2

[30] Kadarmideen, H.N. and Wegmann, S. (2003) Genetic Parameters for Body Condition Score and Its Relationship with Type and Production Traits in Swiss Holsteins. Journal of Dairy Science, 86, 3685-3693. http://dx.doi.org/10.3168/jds.S0022-0302(03)73974-5

[31] Pryce, J.E., Coffey, M.P. and Brotherstone, S. (2000) The Genetic Relationship between Calving Intervals, Body Condition Score and Linear Type and Management Traits in Registered Holsteins. Journal of Dairy Science, 83, 26642671. http://dx.doi.org/10.3168/jds.S0022-0302(00)75160-5

[32] Jairath, L., Dekkers, J.C.M., Schaeffer, L.R., Liu, Z., Burnside, E.B. and Kolstad, B. (1998) Genetic Evaluation for Herd Life in Canada. Journal of Dairy Science, 81, 550-562. http://dx.doi.org/10.3168/jds.S0022-0302(98)75607-3

[33] Astis, B.S., Gonzalez, M.J.V., Ayala, G.L. and Monge, V.A. (2002) The Influence of Pelvic Conformation on Incidences of Uro-Vagina: An Epidemiological Study. Proceedings of the XXII World Buiatrics Congress, Hanover, 18-23 August 2002, 362-365.

[34] Hansen, L.B., Cole, J.B., Marx, G.D. and Seykora, A.J. (1999) Productive Life and Reasons for Disposal of Holstein Cows Selected for Large versus Small Body Size. Journal of Dairy Science, 82, 795-801. http://dx.doi.org/10.3168/jds.S0022-0302(99)75298-7

[35] Sölkner, J. and Petschina, R. (1999) Relationship between Type Traits and Longevity in Austrian Simmental Cattle. Proceedings of the International Workshop on EU Concerned Action on Genetic Improvement of Functional Traits in Cattle (GIFT); Longevity, Jouy-en-Josas, May 1999, Bulletin 21, 91-95.

[36] Cassandro, M., Gallo, L., Carnier, P., Penzo, N. and Bittante, G. (1999) Collecting Functional Traits in Dairy Herds: Overview of a Program Currently Running in Italy. Proceedings of the International Workshop on EU Concerned Action on Genetic Improvement of Functional Traits in Cattle (GIFT), Breeding Goals and Selection Schemes, Wageningen, 7-9 November 1999, Bulletin 23, 123-130.

[37] Strapak, P., Candrák, J. and Aumann, J. (2005) Relationship between Longevity and Selected Production, Reproduction and Type Traits. Czech Journal of Animal Science, 50, 1-6.

[38] Burke, B.P. and Funk, D.A. (1993) Relationship of Linear Type Traits and Herd Life under Different Management Systems. Journal of Dairy Science, 76, 2773-2782. http://dx.doi.org/10.3168/jds.S0022-0302(93)77615-8 